Methodological approaches to conducting pooled cross-sectional time series analysis: the example of the association between all-cause mortality and per capita alcohol consumption for men in 15 European states

Gmel, Gerhard ; Rehm, Jürgen ; Frick, Ulrich

DOI: https://doi.org/10.1159/000050730

Posted at the Zurich Open Repository and Archive, University of Zurich

ZORA URL: https://doi.org/10.5167/uzh-94617

Journal Article

Published Version

Originally published at:

Gmel, Gerhard; Rehm, Jürgen; Frick, Ulrich (2001). Methodological approaches to conducting pooled cross-sectional time series analysis: the example of the association between all-cause mortality and per capita alcohol consumption for men in 15 European states. European Addiction Research, 7(3):128-137. DOI: https://doi.org/10.1159/000050730 


\title{
Methodological Approaches to Conducting Pooled Cross-Sectional Time Series Analysis: The Example of the Association between All-Cause Mortality and per capita Alcohol Consumption for Men in 15 European States
}

\author{
Gerhard Gmela Jürgen Rehm ${ }^{a-d}$ Ulrich Frick ${ }^{\mathrm{e}}$ \\ a Swiss Institute for the Prevention of Alcohol and Other Drug Problems, Lausanne; 'bddiction Research Institute, \\ Zürich, Switzerland; 'Centre for Addiction and Mental Health, Toronto, Ont.; dUniversity of Toronto, Ont., Canada, \\ and e University of Regensburg, Germany
}

\section{Key Words}

Volume of drinking - Patterns of drinking - All-cause mortality $\cdot$ Pooled cross-sectional time series

\begin{abstract}
Aim: To compare different statistical models in order to estimate the association of alcohol consumption and total mortality when time series data stem from different regions. Data and Methods: Data on per capita consumption in 15 European countries were combined with standardized mortality rates covering different periods between 1950 and 1995. An indicator of region-specific drinking patterns was measured without reference to a concrete time point, thus generating a hierarchical data structure. Two groups of models were compared: pooled cross-sectional time series models with different error structures and hierarchical linear models (random coefficient models). Results: If historical time is not controlled for in cross-sectional models, this might result in estimating a negative association between alcohol consumption and total mortality. Hierarchical linear models or cross-sectional models controlling for historical time, however, resulted in the expected positive association.
\end{abstract}

\section{KARGER}

Fax +41613061234

E-Mail karger@karger.ch

www.karger.com

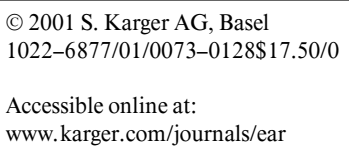

Only hierarchical linear models were able to adequately estimate the moderating effect of drinking patterns on the association between alcohol consumption and total mortality. Conclusion: For pooled cross-sectional time series data, control for the potential impact of historical time is of utmost importance. Hierarchical linear models constitute a superior alternative to analyze such complex data sets, especially as time-independent characteristics of regions can be implemented in the model.

Copyright $@ 2001$ S. Karger AG, Basel

\section{Introduction}

The analysis of the association between alcohol consumption and mortality (e.g. liver cirrhosis, homicides, traffic accidents, suicides, heart disease mortality or allcause mortality) with time series of aggregate level data has increasingly become an alternative to individual level studies. One advantage of aggregate level data is that they are usually easily obtainable from official sources and therefore facilitate cross-cultural comparisons across a wide range of countries. A recent prominent example is the European Comparative Alcohol Study (ECAS; see 
February 2001 supplement of Addiction). The present study describes models for the joint analysis of time series data across different countries, called pooled cross-sectional time series models. Pooled cross-sectional time series have been used in the alcohol field, for example to analyze the association between alcohol consumption and suicide [1] or alcohol consumption and all-cause mortality [2]. The models used in the literature, however, differed substantially. The present paper uses as an example the analysis of the association between alcohol consumption and all-cause mortality in $14 \mathrm{EU}$ states and Norway for men aged 15 years or older, to further elucidate the differences across pooled cross-sectional time series models.

What is a pooled cross-sectional time series analysis? Time series data, e.g. per capita alcohol consumption in a country over time, are combined with cross-sectional data, e.g. per capita consumption data at single time points across different countries. The reasons for using this method may be manifold. On the one hand, it may be simply for statistical reasons as often single univariate time series are too short for conventional time series techniques [for time series analysis in the alcohol research field, see 3], and pooling of series across sections (e.g. countries, regions) may greatly increase sample size. On the other hand, there may be an intrinsic interest in modelling the differences in parameter estimates or in testing their homogeneity across sections. For example, the wetness of a culture may be associated with the strength and the direction of the association between alcohol consumption and suicides [4].

Of course, both reasons may apply at the same time. For example, in the context of estimating the global burden of disease from alcohol consumption it is assumed that the burden from certain chronic diseases is related to total volume of alcohol consumption only, and therefore the association between consumption and disease should depend on volume only, independent of culture-specific drinking patterns [5]. Such a constant association across sections would benefit from pooling data simply by increasing the number of observations and therefore increasing the reliability and stability of estimates. In addition, it could be tested whether such an assumption of a constant association holds. To the contrary, for certain outcomes it is assumed that drinking patterns (e.g. regularity of drinking with meals, binge drinking, etc.) that vary with cross-sections (countries) are relevant for assessing the association with volume, and therefore differences across sections should be part of the models [6].

The simplest model of a pooled time series design, called the 'constant coefficient model' [7] or 'population- averaged model with independent errors' [8], would stack all observations across time points and cross-sections into one data file and analyze the combined data by standard regression techniques (e.g. OLS regression for an intervalscaled dependent variable). Such a model would assume that observations across time and cross-sections are completely independent of each other. This means that neither the ordering in time nor the grouping within crosssections must be obeyed and, hence, that there is no association between the time points within a cross-section or between time points between cross-sections and that there is no relationship between the cross-sections within a time point or between time points. The constant coefficient model often serves as a reference model only. It could be written as follows:

$$
\mathrm{Y}_{\mathrm{nt}}=\mathrm{X}_{\mathrm{knt}} \beta_{\mathrm{k}}+\varepsilon_{\mathrm{nt}}
$$

where $n=1 . . \mathrm{N}$ index of cross-sections, $\mathrm{t}=1 . . \mathrm{T}$ index of time points, and $\mathrm{k}=1 \mathrm{~K}$ index of explanatory variables.

Assumptions of the standard linear model may easily be violated, however.

Examples:

(1) Zero expectation of errors for all cross-sections

$\mathrm{E}\left(\varepsilon_{\mathrm{nt}}\right)=0$ for all $\mathrm{n}, \mathrm{t}$

(2) Constant error variance for all cross-sections

$\mathrm{V}\left(\varepsilon_{\mathrm{nt}}\right)=\sigma^{2}$ for all $\mathrm{n}, \mathrm{t}$

(3) Uncorrelatedness of errors within and across crosssections

$$
\operatorname{COV}\left(\varepsilon_{\mathrm{it}}, \varepsilon_{\mathrm{jt}}\right)=0 \text { for any } \mathrm{i}, \mathrm{j}, \mathrm{t} \text {. }
$$

Assumptions 1 and 2 in the present study would be violated when, for example, mortality in a country is always higher than the overall prediction across all countries and all time points. For such a country all errors would be positive. Similarly, the error variances may vary across countries (heteroscedasticity) due to the fact that mortality is measured with different reliability in different countries, for example. Typical for time series data, errors may be correlated within a cross-section (autocorrelation), but also at the same time point across sections. An example for such a pattern may be seen in the Nordic countries where there are similar alcohol policies.

The present study compares several pooled cross-sectional time series models for the association between per capita alcohol consumption and all-cause mortality for males aged 15 years and older. Models used can be distinguished by models that attempt to estimate a single 'population-averaged' association between exposure (consump- 
Table 1. Patterns of drinking for analysis of European data (categories and scoring males only)

\begin{tabular}{|c|c|c|}
\hline Pattern & Scoring for the summary measure of pattern value & Link to disease burden \\
\hline $\begin{array}{l}\text { Proportion of abstainers } \\
\text { in population }\end{array}$ & $\begin{array}{l}0=<20 \% \text { of abstainers } \\
1=20 \% \text { or more abstainers }\end{array}$ & $\begin{array}{l}\text { The same per capita consumption will have more } \\
\text { detrimental effects in countries where drinking is } \\
\text { concentrated on fewer people }\end{array}$ \\
\hline \multirow[t]{5}{*}{$\begin{array}{l}\text { Heavy drinking occasions } \\
\text { Percentages of } 4+ \\
\text { Daily drinking } \\
\text { Frequency of drinking } \\
\text { Adult drunkenness } \\
\text { Festive drinking }\end{array}$} & 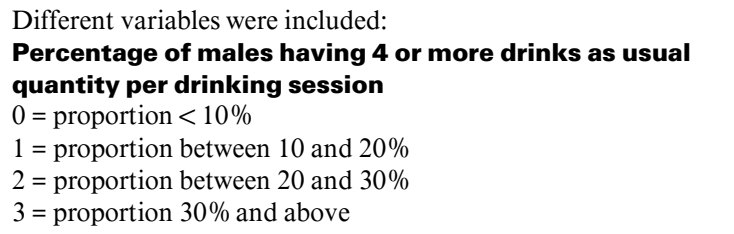 & \multirow[t]{5}{*}{$\begin{array}{l}\text { The more condensed the same amount of alcohol is } \\
\text { consumed the more detrimental the consequences } \\
\text { [32] }\end{array}$} \\
\hline & $\begin{array}{l}\text { Daily drinking } \\
0=20 \% \text { and more consume alcohol daily } \\
1=<20 \% \text { consume alcohol }\end{array}$ & \\
\hline & $\begin{array}{l}\text { Frequency of drinking } \\
0=>50 \% \text { drink weekly } \\
1=30-50 \% \text { drink weekly } \\
2=<30 \% \text { drink weekly }\end{array}$ & \\
\hline & $\begin{array}{l}\text { Adult drunkenness } \\
0=\text { most male drinkers never get drunk at all } \\
1=\text { most male drinkers get drunk some of the times they } \\
\text { are drinking } \\
2=\text { most male drinkers often get drunk when they are drinking } \\
3=\text { most male drinkers usually get drunk when they are drinking }\end{array}$ & \\
\hline & $\begin{array}{l}\text { Festive drinking } \\
0=\text { fiesta drinking rarely or never occurs } \\
1=\text { fiesta drinking sometimes occurs } \\
2=\text { fiesta drinking commonly occurs (at least once a year whole } \\
\quad \text { communities join in a celebration including drinking } \\
\quad \text { over } 2 \text { or more days) }\end{array}$ & \\
\hline Drinking with meals & $\begin{aligned} 0= & \text { drinking customary at } 1 \text { or more meals per day } \\
1= & \text { drinking customary often with meals } \\
2= & \text { drinking customary sometimes at meals (intermittently, or } \\
& \text { on special occasions only) or rarely or never with meals }\end{aligned}$ & $\begin{array}{l}\text { Drinking with meals has been shown in epidemiology } \\
\text { to be less detrimental than drinking outside meals. } \\
\text { There is also biological evidence as alcohol consumed } \\
\text { with meals was found to reduce the high levels of } \\
\text { blood lipids that occur after eating [33] }\end{array}$ \\
\hline $\begin{array}{l}\text { Young men having } \\
\text { highest volume }\end{array}$ & $\begin{aligned} 0= & \text { peak of distribution of alcohol consumption is above } \\
& \text { age } 30, \text { e.g. highest consuming age group is older than } 30 \\
1= & \text { peak of distribution of alcohol consumption is below age } 30\end{aligned}$ & $\begin{array}{l}\text { Most harm indicators include time considerations } \\
\text { (years of life lost, age weighting in DALYs) [34] }\end{array}$ \\
\hline $\begin{array}{l}\text { Percent of young men getting } \\
\text { drunk at least once yearly }\end{array}$ & $\begin{array}{l}0=<40 \% \text { got drunk within the last month at least once } \\
1=40 \% \text { and more got drunk within the last month at least once }\end{array}$ & $\begin{array}{l}\text { Same reasoning as for adult drunkenness (see above) } \\
\text { From ESPAD } 1995 \text { survey [13] }\end{array}$ \\
\hline Unrecorded consumption & $\begin{array}{l}0=\text { unrecorded consumption estimated to be below } 0.5 \text { liters } \\
\text { per capita } \\
1=\text { unrecorded consumption estimated to be between } 0.5 \text { and } \\
1.5 \text { liters per capita } \\
2=\text { unrecorded consumption estimated to be above } 1.5 \text { liters } \\
\text { per capita } \\
\text { (note that the range in the countries included in the model did } \\
\text { not go beyond } 2.5 \text { liters of estimated unrecorded per capita } \\
\text { consumption) }\end{array}$ & $\begin{array}{l}\text { The higher the unrecorded consumption the more } \\
\text { alcohol is consumed in reality. Thus, the same level } \\
\text { of recorded consumption is more detrimental, if there } \\
\text { is more unrecorded consumption } \\
\text { This variable was changed after the January } 2001 \\
\text { conference and estimates of unrecorded consumption } \\
\text { are now included into the overall per capita estimates } \\
\text { [14, see Appendix } 8.2]\end{array}$ \\
\hline $\begin{array}{l}\text { Norms about alcohol-related } \\
\text { violence }\end{array}$ & & $\begin{array}{l}\text { The more violence under the influence is culturally } \\
\text { accepted the more burden will come from drinking } \\
\text { Problematic confounding with outcome was dropped } \\
\text { from final analysis }\end{array}$ \\
\hline
\end{tabular}

DALY = Disability adjusted life year.

This analysis is based on the data collected from the WHO key informants survey 2000 [14]. The scoring is based on the fact that optimal scoring of the full survey (including non-European countries) basically lead to the same results as a simple additive scoring. Thus, for this survey a simple additive scoring was used. Specific data on youth and young adults only available in Europe, are included as well. 
tion) and outcome (all-cause mortality) and models aimed at modelling differences in associations across sections. In addition, we will look at the potential effects of controlling for confounding. Controlling for confounding is particularly difficult in aggregate level studies, especially in pooled cross-sectional time series studies as data of potential confounders must be available for all time points and in all cross-sections. This usually limits the inclusion of many potentially relevant confounders. In the present study, time (measured in years) is used to partially control for both confounding and omitted variable bias [for a similar technique, see 1; for such an approach in the alcohol field, see 9].

\section{Methods}

Data

Per capita consumption and data of all-cause mortality of 15 countries were obtained from the ECAS, and are extensively described in the February 2001 supplement of Addiction [10]. Briefly, per capita alcohol consumption, measured in liters of $100 \%$ alcohol per inhabitant 15 years and older, was obtained from the Brewers Association of Canada [11]. Age-specific data on all-cause mortality were obtained from the World Health Organization (WHO) Mortality Database and standardized to the WHO 1998 standard population [12].

Data on patterns of drinking were taken from a survey on relevant drinking characteristics of key informants by the WHO in 2000 (see appendix 8.1 for a full copy of the questionnaire) as well as from ECAS (estimates for unrecorded consumption) and from the ESPAD study [13]. Table 1 gives an overview on pattern values; the rationale for assessing them can be found in Rehm et al. [14]. Please note that for the final comparative risk analysis on the burden of alcohol, a simpler pattern value was used [for a detailed discussion on the underlying reasons, see 14]. Key informants from more than 50 countries worldwide responded to the WHO questionnaire.

\section{Population-Averaged Models}

Related to the corresponding procedures in Stata [8] two sets of models were run. The first set uses GEE estimation [15] and allows different descriptions of the correlation matrix within cross-sections subject to the constraint that the same correlation matrix applies to all cross-sections. The following models were used, with $\mathrm{R}_{\mathrm{t}, \mathrm{s}}$ being the $t, s$ element of the correlation matrix, where $t$ and $s$ describe time points (here, years):

(1) Independent structure, i.e. $\mathrm{R}_{\mathrm{t}, \mathrm{s}}=1$ for $\mathrm{t}=\mathrm{s}$ and 0 otherwise. This structure is equivalent to a model for which all observations are pooled into one file and analyzed as if all data come from the same underlying population.

(2) Autoregressive (AR) structure, i.e. for an autoregressive structure of order $1, R_{t, s}=1$ for $t=s$ and $\rho^{|t-s|}$ otherwise. This structure models an exponentially decaying correlation in time within a crosssection, hence it assumes that the less observations are correlated the more they are separated in time.

(3) Stationary structure, i.e. for stationarity of order $1, R_{t, s}=1$ for $\mathrm{t}=\mathrm{s}, \rho$ for $|\mathrm{t}-\mathrm{s}|=1$, and 0 otherwise. This structure permits a correlation only between two consecutive time points.
(4) Nonstationary structure, i.e. for nonstationarity of order g, $\mathrm{R}_{\mathrm{t}, \mathrm{s}}=1$ for $\mathrm{t}=\mathrm{s}, \rho_{\mathrm{ts}}$ for $\mathrm{g}>=|\mathrm{t}-\mathrm{s}|>0$. This structure permits correlations for all observations separated by up to $g$ time points. The correlation may differ with the number of time points between two observations, and with the location in time (i.e. a different correlation between 1950 and 1951 and between 1974 and 1975). A completely unconstrained correlation matrix would be a nonstationary structure with $\mathrm{g}=\mathrm{n}-1$ (number of time points).

The second set of models uses GLS estimation. Compared with the GEE models this set relaxes the restrictions of sameness within cross-section correlation matrices. Hence, it permits the estimation of heteroscedastic variances across sections, and the estimation of cross-sectional specific autoregression. The models are restricted to autoregressive models of order 1.

\section{Random Coefficient Models}

The main difference between random coefficient models to population-averaged models is that the association between the outcome (mortality) and the independent variables (per capita consumption; time as a control variable) is not fixed to be constant across sections. The rationale of these models in the present context is described by Rehm and Gmel [16] and others [17-20]. Briefly, intercept and slopes are assumed to vary randomly across sections. In a two-level analysis this variation can be predicted by variables at the level of the cross-sections (e.g. per region). In the present study the variation in the slopes of per capita consumption to predict mortality will be explained by drinking patterns per country. Thus, it is assumed that the association between per capita consumption and mortality is moderated by drinking pattern. The corresponding model (without control variables) can be described as follows:

$$
\text { Mortality rate }_{\mathrm{tc}}=\beta_{0 \mathrm{c}}+\beta_{1 \mathrm{c}} \text { alcohol }_{\mathrm{tc}}+\varepsilon
$$

where $t=$ index of time and $c=$ index of countries.

The coefficients $\beta_{0 \mathrm{c}}$ and $\beta_{1 \mathrm{c}}$ symbolize now random variables which vary across countries. Therefore, the simplest way to model this random variation is given by the following equation:

$$
\beta_{0 c}=\gamma_{00}+\mu_{0 c}
$$

whereas $\gamma_{00}=$ global intercept of mortality rate, $\mu_{0 c}=$ region specific variation of intercepts of mortality rates, and similarly:

$$
\beta_{1 \mathrm{c}} \gamma_{10}+\mu_{1 \mathrm{c}}
$$

with $\gamma_{10}=$ global slope of impact of alcohol (level 2 intercept of alcohol), and $\mu_{1 \mathrm{c}}=$ region-specific variation of alcohol impact.

Influences of country-specific drinking patterns on the slopes of per capita consumption can then be modelled as:

$$
\beta_{1 \mathrm{c}}=\gamma_{11}=\text { pattern }_{\mathrm{c}}+\mu_{1 \mathrm{c}} \text {. }
$$

\section{Results}

\section{Descriptive Analysis}

Table 2 gives an overview of the variables used in the present study. It shows that there is a lot of variability in the association, aggregated over the study period, between alcohol consumption and mortality across countries. As an example, Finland with the highest mortality rate has one of the lowest per capita consumptions. On the other 
Table 2. Study period, averaged per capita consumption, averaged mortality rates and pattern weights for countries in the study

\begin{tabular}{llllr}
\hline Country & $\begin{array}{l}\text { Range of } \\
\text { observation }\end{array}$ & $\begin{array}{l}\text { Mean } \\
\text { standardized } \\
\text { mortality rate } \\
\text { over the period }\end{array}$ & $\begin{array}{l}\text { Mean per } \\
\text { capita } \\
\text { consumption } \\
\text { over the period }\end{array}$ & $\begin{array}{l}\text { Pattern } \\
\text { weight }\end{array}$ \\
\hline The Netherlands & $1951-1995$ & $1,320.3$ & 7.8 & 7 \\
Austria & $1956-1995$ & $1,608.8$ & 13.2 & 5 \\
Belgium & $1955-1995$ & $1,582.1$ & 11.2 & 8 \\
Denmark & $1952-1993$ & $1,390.0$ & 9.2 & 8 \\
Finland & $1953-1995$ & $1,757.4$ & 6.4 & 15 \\
France & $1951-1995$ & $1,524.0$ & 21.5 & 3 \\
Greece & $1962-1995$ & $1,183.0$ & 9.3 & 5 \\
Ireland & $1951-1994$ & $1,625.2$ & 8.0 & 12 \\
Italy & $1952-1993$ & $1,454.2$ & 15.7 & 3 \\
Norway & $1952-1995$ & $1,291.6$ & 4.5 & 13 \\
Portugal & $1956-1995$ & $1,722.9$ & 15.9 & 6 \\
Spain & $1952-1995$ & $1,386.1$ & 14.1 & 6 \\
Sweden & $1952-1995$ & $1,294.5$ & 6.5 & 11 \\
United Kingdom & $1951-1995$ & $1,575.2$ & 7.6 & 10 \\
West Germany & $1953-1990$ & $1,613.1$ & 11.6 & 6 \\
\hline
\end{tabular}

Table 3. Population-averaged models, GEE estimations of parameters for the per capita consumption effect on mortality

\begin{tabular}{lrllll}
\hline Model & \multicolumn{2}{c}{ Crude } & & \multicolumn{2}{c}{ Adjusted for time } \\
\cline { 2 - 3 } \cline { 5 - 6 } \cline { 5 - 6 } & slope & SE of slope & & slope & SE of slope \\
\hline Independence & 6.40 & 1.78 & & 11.17 & 1.43 \\
Autoregressive order 1 & 16.28 & 3.75 & & 19.20 & 2.89 \\
Autoregressive order 2 & 14.56 & 3.75 & & 17.07 & 2.71 \\
Nonstationary order 1 & 6.01 & 2.50 & & 11.04 & 1.99 \\
Nonstationary order 2 & 6.15 & 3.00 & & 11.44 & 2.39 \\
Stationary order 1 & 6.06 & 2.50 & & 10.96 & 2.01 \\
Stationary order 2 & 6.33 & 3.01 & & 11.53 & 2.42
\end{tabular}

hand, France with the highest per capita consumption (more than three times higher than Finland or Sweden) is ranked in the middle of all countries as regards mortality.

As can be seen in figures 1 and 2, the development of per capita consumption and standardized mortality of men over the study period shows an increasing homogeneity of both variables with time. Whereas standardized mortality is generally declining, the greater homogeneity of per capita consumption in the 1990s compared with the 1950s and 1960s also comes from different trends in per capita consumption: consumption tends to decrease in former high-consumption countries and increases or remains stable in low- and medium-consumption countries.

\section{Population-Averaged Models}

The first set of models (table 3) estimates models with a single (fixed) regression coefficient for alcohol consumption to predict mortality. The models permit estimation of the within-group correlation matrix.

The comparison of the different models shows that adjusting for linear time trends results in estimates of the impact of per capita consumption on mortality (regression slopes for alcohol consumption), which are higher (almost twice as high) than the crude estimates. The only crude models that result in estimates similar to the adjusted models are those with an autoregressive withingroup correlation structure. The difference between the autoregressive correlation structures and the other correlation structures (i.e. independence, stationary and nonstationary) is that correlations are not assumed to be 0 for a time lag exceeding a certain length (here restricted to 2 years). Hence, it appears that observations are correlated even for longer time intervals. In addition, adjusting for time in a linear function seems to cover most of this autocorrelation structure.

The second set of models (table 4) relaxes the restriction of homogeneous correlation matrices across sections, but is more restrictive as regards the order of autocorrelation. In addition, heteroscedastic models (i.e. varying variances across sections) can be estimated. Of course, the homoscedastic independence model and the homoscedastic model for constant autoregression across sections should result in approximately the same estimates as before, besides differences due to estimation methods (GEE versus GLS).

Firstly, an inspection of table 4 reveals that the assumption of independence of observations without adjusting for (linear) time trends seems to result in underestimation of the effect of alcohol consumption on mortality (see also the findings on random coefficient models below). Secondly, it seems to be of minor importance whether the autoregression of disturbances is estimated to be section-specific or assumed to be constant across sections (= countries). Thirdly, heteroscedasticity affects only crude models without adjusting for time trends. The inclusion of a linear time trend seems to reduce heteroscedasticity. 


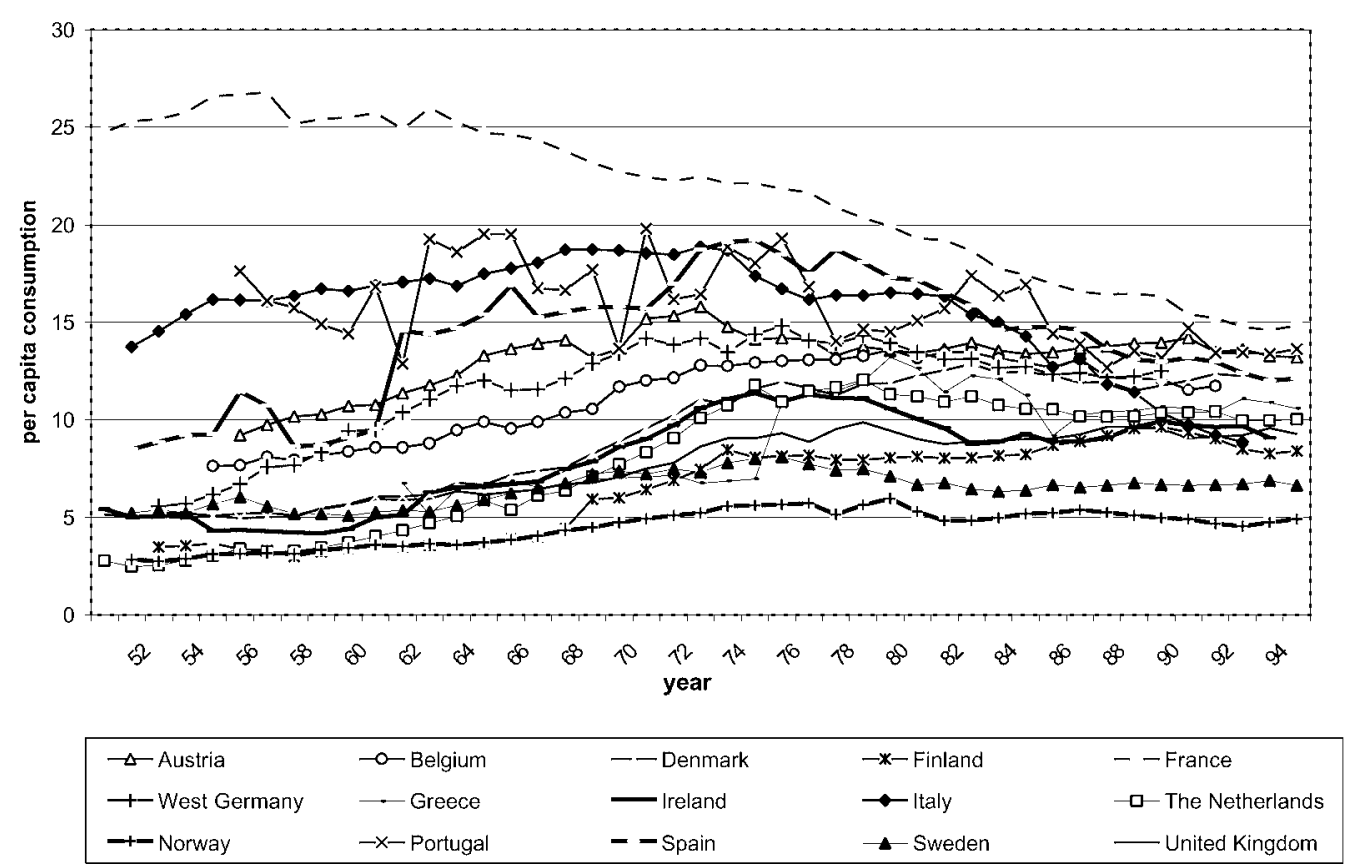

Fig. 1. Per capita alcohol consumption in the 15 study countries.

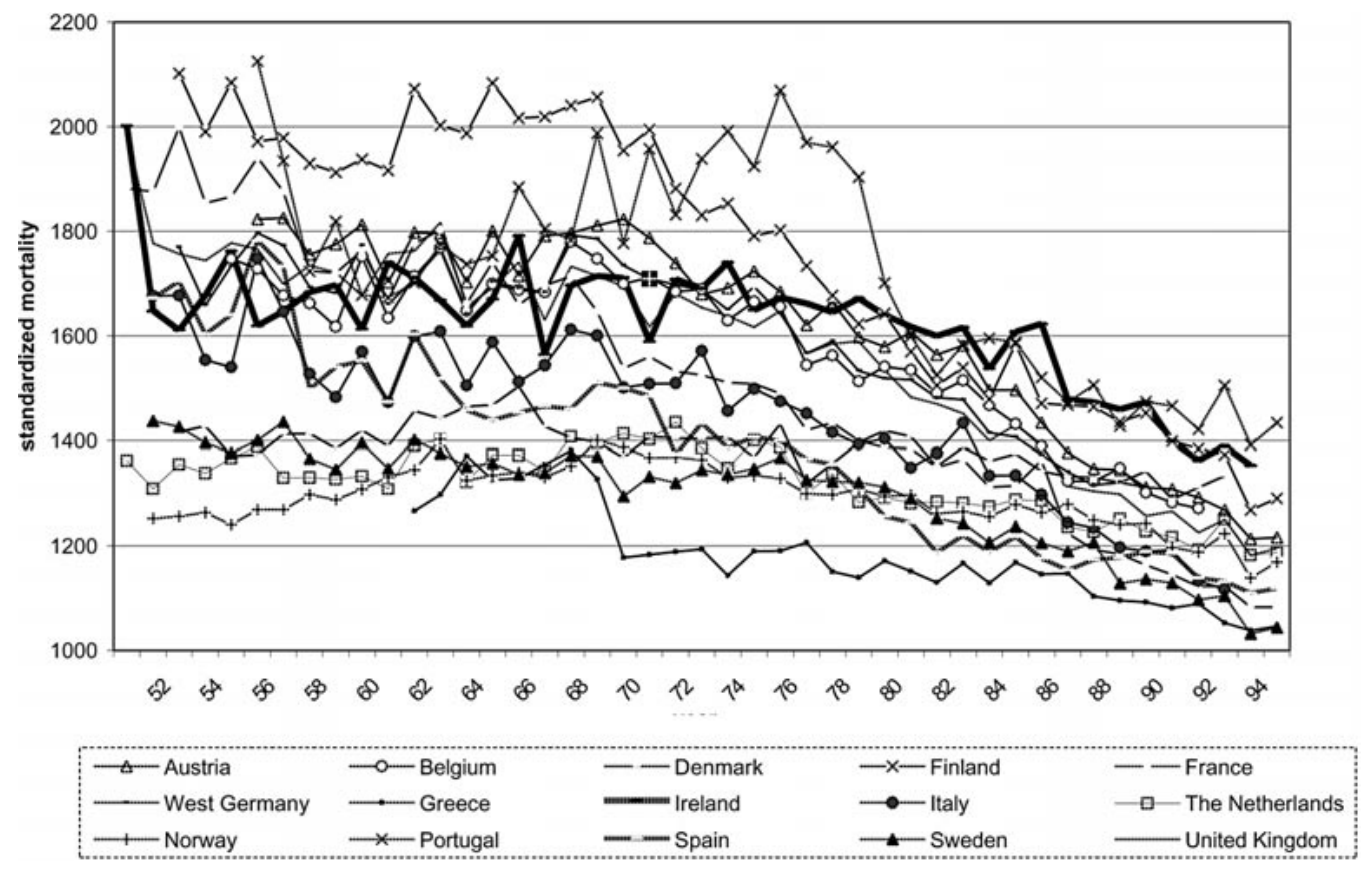

Fig. 2. Standardized mortality in the 15 study countries. 
Table 4. Population-averaged models, GLS estimations of parameters for the per capita consumption effect on mortality

\begin{tabular}{llllll}
\hline Model & \multicolumn{2}{l}{ Crude } & & \multicolumn{2}{c}{ Adjusted for time } \\
\cline { 6 - 7 } \cline { 5 - 6 } & slope & SE of slope & slope & SE of slope \\
\hline Independence & 6.40 & 1.78 & & 11.17 & 1.42 \\
Independence, heteroscedastic & 5.79 & 1.72 & & 10.09 & 1.44 \\
Autoregressive (AR), AR constant across sections & 17.16 & 2.98 & & 17.75 & 2.57 \\
Autoregressive, AR constant across sections, heteroscedastic & 12.25 & 2.74 & & 18.32 & 2.64 \\
Autoregressive, section-specific AR & 15.09 & 2.96 & & 15.23 & 2.45 \\
Autoregressive, section-specific AR, heteroscedastic & 11.37 & 3.13 & & 15.98 & 2.56 \\
\hline
\end{tabular}

Table 5. Random coefficient models for the per capita consumption effect on mortality, estimated with the assumptions of independent errors and homoscedastic variances

Table 6. Two-level random coefficient models ${ }^{1}$ for the alcohol consumption effect on mortality, adjusted for time

\begin{tabular}{lllllll}
\hline Model & \multicolumn{2}{l}{ Crude } & & & \multicolumn{2}{l}{ Adjusted for time } \\
& slope & SE of slope & & slope & SE of slope \\
\hline 2-step OLS estimation with Stata & -14.62 & 12.18 & & 28.04 & 5.82 \\
Iterative GLS estimation with MLWin & -14.53 & 11.45 & & 26.11 & 4.44 \\
Restricted ML estimation with HLM & -14.62 & 11.45 & & 26.36 & 4.49 \\
\hline
\end{tabular}

\begin{tabular}{lrrrrr}
\hline & \multicolumn{2}{l}{$\begin{array}{l}\text { Homoscedastic } \\
\text { level-1 variances }\end{array}$} & & \multicolumn{2}{l}{$\begin{array}{l}\text { Heteroscedastic } \\
\text { level-1 variances }\end{array}$} \\
\cline { 2 - 3 } & coefficient & SE & & coefficient & SE \\
\hline Global intercept of mortality $\left(\gamma_{00}\right)$ & $2,155.74$ & 129.02 & & $2,221.90$ & 136.33 \\
Level 2 intercept of time $\left(\gamma_{20}\right)$ & -12.92 & 1.45 & & -13.63 & 1.52 \\
Level 2 intercept of alcohol $\left(\gamma_{10}\right)$ & 2.57 & 6.25 & & 3.88 & 5.79 \\
Level 2 slope of drinking patterns $\left(\gamma_{11}\right)$ & 3.30 & 0.43 & & 3.02 & 0.41 \\
\hline Models were estimated with HLM. & & & & & \\
\hline
\end{tabular}

\section{Random Coefficient Models}

As summarized in table 5 the choice of different software programs (Stata, HLM, Mlwin) and associated estimation algorithms only marginally affects parameter estimates [for a brief review of different estimation algorithms, see 19]. Random coefficient models, however, result in huge differences between the estimated crude and adjusted effects of alcohol consumption on mortality. It should be noted that for all coefficients random variation was highly significant $(p<0.001)$ and therefore the hypothesis of constant coefficients across sections could be rejected for all parameters (i.e. intercept, slope of alcohol consumption, slope of time; results not shown).
The surprising finding of table 5 is that unadjusted random coefficient models result in a negative though nonsignificant association between alcohol consumption and mortality, which is an apparent contradiction to all models estimated so far. The reason is that random coefficient models do not estimate one single (fixed) coefficient for alcohol consumption across all countries, but instead a multitude of country-specific coefficients. Hence, the coefficients in table 5 can be seen as the averages of country-specific estimates (with random variation around it, see equation 2 in the method section). As described in figures 1 and 2, mortality is decreasing in all countries. However, alcohol consumption is, with a few exceptions, 
increasing over the whole period (i.e. either generally increasing or increasing in the first two decades and then remaining stable). Exceptions are Portugal, Italy, and France displaying a decreasing per capita consumption. Hence, with the exception of these three countries, the unadjusted association between mortality and alcohol consumption is negative in each country (results not shown). That such a negative association has not been found in the unadjusted population-averaged models corresponds to the well-known analysis-of-covariance problem, namely that the association between groups may be inversely related to the association within groups. Whereas the unadjusted association between alcohol consumption and mortality within countries is negative for most countries, it is positive between countries. For example, the correlation between mean consumption and mean mortality in table 2 is 0.26 .

When the above-described trend in time was controlled for in random coefficient models, estimates of the alcohol consumption parameters were even higher than for the adjusted population-averaged models (i.e. $>26$ ). The advantage of random coefficient models is that not only the association between consumption and mortality can vary across countries, but also the association with the control variable time. Thus, the adjustment of time can be analyzed in a country-specific manner.

As a final step the effect of drinking patterns on the regression slope of alcohol consumption was modelled (table 6) with two models (i.e. with and without the assumption of heteroscedasticity of level-1 variances).

The interpretation of coefficients for alcohol consumption is now different from the other random coefficient models. The effect of alcohol consumption is the joint effect of the alcohol intercept plus the effect of the pattern weight. Drinking patterns significantly predict the variation in the slopes of alcohol consumption, hence, the effect of alcohol consumption on mortality (table 7).

To exemplify the meaning of these models including cross-level interaction for the homoscedastic models: In a country with a pattern weight of 5 it would be predicted that an increase of 1 liter of $100 \%$ ethanol would result in an increase in the standardized mortality rate of 19.05 $(=2.57+(5 \cdot 3.30)$; note rounding errors $)$, whereas in a country with a pattern weight of 10 per 1 liter increase would result in a much higher increase in the mortality rate by $35.54(=2.57+(10 \cdot 3.30)$; note rounding errors $)$.

Again, heteroscedasticity only marginally affects the parameter estimates. Permitting heteroscedasticity slightly increases the effect of alcohol consumption in countries with less detrimental drinking patterns (i.e. low values of
Table 7. Predicted effect of per capita consumption of 1 liter by pattern weights, all other things being equal

\begin{tabular}{lllll}
\hline & \multicolumn{4}{l}{ Pattern weight } \\
\cline { 2 - 5 } & 1 & 5 & 10 & 15 \\
\hline Homoscedastic level-1 variance & 5.87 & 19.05 & 35.54 & 52.02 \\
Heteroscedastic level-1 variance & 6.90 & 18.97 & 34.06 & 49.15 \\
\hline
\end{tabular}

the pattern variables) and reduces the effect in countries with more detrimental drinking patterns.

\section{Discussion}

The aim of the present study has been to compare several models for pooled cross-sectional time series analysis. It should be noted that this comparison is far from being comprehensive. All models allowing for cross-sectional correlations, e.g. correlation of residuals between two countries, have been omitted [for such an approach in the alcohol field, see 2]. These models, however, need socalled balanced panels, i.e. that each panel ( = cross-section) has the same number of time points and covers the same time period. Although such models would have been possible in the present study by simply restricting all series to a common time period (1962-1990; table 1), the present study should be seen in the broader context of the global burden of disease study [21]. The global burden of disease study involves more countries, especially developing countries or countries with a shorter history (e.g. the former Soviet Republics), for which too many missing values across countries would not allow the analysis of balanced panels or would need an unacceptable loss of information due to listwise deletion of time points. Some other models would have been theoretically feasible, but did not converge, probably pointing to major problems of time series analysis in the alcohol field: the shortness of series and the lack of variability in observed values resulting in colinearity problems [3]. These theoretically feasible models will be discussed below together with the findings from the present study.

One of the main findings of the present study is that the inclusion of control variables may heavily affect parameter estimates of the association between the outcome and exposure under study. Concurrent historical trends in both the outcome and the exposure may result in biased estimates of the association when not sufficiently 
controlled for. In the present study mortality in general declined.

Alcohol consumption, on the other hand, showed diverging trends (e.g. decreasing trends in high-consumption countries and increasing or stable trends in low-consumption countries). In the present study we used a linear time trend to adjust for unknown confounding. Other techniques such as the use of dummy variables instead of a linear trend [1], quadratic or higher polynomial trends [22], or differencing of series [23] may be valuable and should be compared in future studies.

It is well known that time series may have autocorrelated residuals resulting in inefficient parameter estimates and biased standard errors [24]. In the present study autocorrelation affected parameter estimates in unadjusted models (i.e. without the inclusion of time as a covariate), but did less so in adjusted models. The reason in the present study may be that the inclusion of time already absorbed much of the autocorrelation as mortality was declining fairly linear. We strongly recommend, however, testing for autocorrelated disturbances in all time series models.

We see the use of multi-level (random coefficient) modelling as a further improvement in pooled cross-sectional time series modelling. As has been demonstrated in the present study, the assumption of a constant association between mortality and alcohol consumption may even result in parameter estimates with an inverse sign (i.e. in the unadjusted models). It should be noted that some pooled cross-sectional models such as the least squares dummy variable (LSDV) model [for an example in the alcohol field, see 1] are in fact sub-models. The LSDV model includes separate intercepts for each crosssection into the equation. Hence, it estimates parallel regression lines for each county. Random coefficient models further permit the slopes to vary across countries. In addition, in multi-level models these variations may be related to differences at the country level. In the present study the variation in the association between per capita alcohol consumption and all-cause mortality could be significantly predicted by different drinking patterns across countries: hypothesized unfavorable drinking pattern predicted a more detrimental impact of per capita consumption on mortality compared to more favorable drinking patterns, which were associated with a less detrimental impact on mortality. There is software that can handle autocorrelation and heteroscedasticity in multi-level models [25, 26]. It should be noted, however, that in the present study the inclusion of autocorrelated disturbances failed to converge. The potential reason for the non-con- vergence might be that the model was already well-specified with the inclusion of random coefficient time trends and the additional inclusion of further parameters therefore might have resulted in colinearity problems. This seems to be a general problem in analysis of aggregate data in the alcohol field, where relatively low variability within series is coupled with relatively short series [for data requirements necessary for correct specification of series, see 27].

It is, however, not likely that the omission of autocorrelated disturbances may have greatly distorted findings, as in general, models for constant alcohol coefficients that adjusted for time trends did not show a large variation in parameter estimates.

Although estimates differed across models, a consistent finding of the present study was that with adequate control for historical time, all models found a positive association between per capita alcohol consumption and all-cause mortality and therefore confirmed similar studies at the aggregate level $[2,28$; for the same data set using different methodology, see 10]. Individual level studies are less clear here, as the relationship between volume of alcohol consumption and mortality is J-shaped for older age categories [29], and the overall association between alcohol consumption and mortality in a population depends on the location of the nadir and the relative proportion of age groups. The present study was also consistent with individual level studies $[30,31]$ showing that patterns of drinking moderate the association between mortality and the volume of drinking in the predicted direction: the more detrimental the drinking patterns were the higher was the impact of per capita consumption on mortality. Such a moderating effect would be overseen in cross-sectional time series analyses that do not take the multi-level structure into account.

\section{Acknowledgements}

Parts of this article have been prepared for presentation at the WHO European Ministerial Conference on Young People and Alcohol at Stockholm, February 19-21, 2001. The WHO, the Swiss Federal Office of Public Health (contract No. 00.001588), the Addiction Research Institute in Zurich, Switzerland, the Swiss Institute for the Prevention of Alcohol and Other Drug Problems, Lausanne, and the Centre for Addiction and Mental Health in Toronto, Ont., Canada, financially supported this study. The authors would like to thank the participants of the WHO experts' meeting on alcohol as a risk factor for the burden of disease at Geneva, Switzerland, January 29-30, 2001 , and the members of the WHO listserve on alcohol as a risk factor for valuable comments in revising prior versions. 


\section{References}

1 Gruenewald PJ, Ponicki WR, Mitchell PR: Suicide rates and alcohol consumption in the United States, 1970-89. Addiction 1995;90: 1063-1075.

2 Her M, Rehm J: Alcohol and all-cause mortality in Europe 1982-1990: A pooled cross-section time-series analysis. Addiction 1998;93: 1335-1340.

3 Rehm J, Gmel G: Aggregate time series regression in the field of alcohol. Addiction, in press.

4 Ramstedt M: Alcohol and suicide in 14 European countries. Addiction 2001;96(suppl 1): 59-75.

5 Gutjahr E, Gmel G, Rehm J: Relation between average alcohol consumption and disease: An overview. Eur Addict Res 2001;7:117-127.

6 Rehm J, Gmel G, Room R, Frick U: Average volume of alcohol consumption, drinking patterns and related burden of mortality in young people in established market economies of Europe. Eur Addict Res 2001;7:148-151.

7 Sayrs LW: Pooled Time Series Analysis. Newbury Park, Sage Press, 1989.

8 StataCorp: Stata Reference Manual, Release 6 - Volume 4 Su-Z. College Station, Stata Press, 1999.

9 Cook PJ, Tauchen G: The effect of liquor taxes on heavy drinking. Bell J Econom 1982;12: 379-390.

10 Norström T: Per capita alcohol consumption and all-cause mortality in 14 European countries. Addiction 2001;96(suppl 1):113-128.

11 Brewers Association of Canada: Alcoholic Beverage Taxation and Control Policies, ed 9. Ottawa, Brewers Association of Canada, 1997.

12 Ahmad OB, Boschi-Pinto C, Lopez AD, Murray $\mathrm{CJL}$, Lozano $\mathrm{R}$, Inoue $\mathrm{M}$ : Age Standardization of Rates: A New WHO World Standard. Geneva, EIP/GPE/EBD, World Health Organization, 1998.

13 Hibell B, Andersson B, Bjarnason T, Kokkevi A, Morgan M, Narusk A: Alcohol and Other Drug Use Among Students in 23 European Countries. Stockholm, Centralförbundet for Alkohol och Narkotikaupplysning, 1997.
14 Rehm J, Monteiro MG, Room R, Gmel G, Jernigan D, Frick U, Graham K: Steps towards constructing a global comparative risk analysis for alcohol consumption: Determining indicators and empirical weights for patterns of drinking, deciding about theoretical minimum, and dealing with different consequences. Eur Addict Res 2001;7:138-147.

15 Liang KY, Zeger SL: Longitudinal data analysis using generalized linear models. Biometrika 1986;73:13-22.

16 Rehm J, Gmel G: Gaps and needs in international alcohol epidemiology. J Subst Use 2000; 5:6-13.

17 Bryk AS, Raudenbush SW: Hierarchical Linear Models: Applications and Data Analysis Methods, vol 1. Newbury Park, Sage Press, 1992.

18 Hox JJ: Applied Multilevel Analysis, ed 2. Amsterdam, TT-Publikaties, 1995.

19 Kreft IGG, De Leeuw J: Introducing Multilevel Modeling, ed 2. London, Sage Press, 1998

20 Frick U, Rehm J, Krischker S, Cording C: Length of stay in a German psychiatric hospital as a function of patient and organizational characteristics - A multilevel analysis. Int $\mathbf{J}$ Meth Psych Res 1999;8:146-161.

21 Rehm J, Gmel G: Applying principles of comparative risk analysis to substance-abuse related burden. Eur Addict Res 2001;7:95-97.

22 Warner J, Her M, Gmel G, Rehm J: Can legislation prevent debauchery? Mother Gin and public health in eighteenth-century England. Am J Public Health 2001;91:375-384.

23 Norström T, Skog O-J: Alcohol and mortality: Methodological and analytical issues in aggregate analyses. Addiction 2001;96(suppl 1):517

24 Greene WH: Econometric Analysis, ed 3. Upper Saddle River, Prentice Hall, 2000.
25 Yang M, Rasbash J, Goldstein H, Barbosa M MLwiN Macros for Advanced Multilevel Modelling. London, Multilevel Models Project, Institute of Education, 1999.

26 Bryk AS, Raudenbush SW, Congdon R: HLM: Hierarchical Linear and Nonlinear Modeling with the HLM/2L and HLM/3L Programs. Chicago, Scientific Software International, 1996.

27 McGee M: Power analysis and sample size determination for well-known time series models; in Yaffee $\mathrm{R}$ (ed): Introduction to Time Series Analysis and Forecasting. San Diego, Academic Press, 2000, pp 481-493.

28 Norström T: Per capita alcohol consumption and total mortality: An analysis of historical data. Addiction 1996;91:339-344.

29 Rehm J, Gutjahr E, Gmel G: Alcohol and allcause mortality: A pooled analysis. Contemp Drug Probl, in press.

30 Puddey IB, Rakic V, Dimmitt SB, Beilin LJ: Influence of pattern of drinking on cardiovascular disease and cardiovascular risk factors A review. Addiction 1999;94:649-663.

31 Rehm J, Greenfield TK, Rogers JD: Average volume of alcohol consumption, patterns of drinking an all-cause mortality. Results from the US National Alcohol Survey. Am J Epidemiol 2001;153:64-71.

32 Walsh GW, Rehm J: Daily drinking and harm Contemp Drug Probl 1996;23:465-478.

33 Veenstra J, Ockhuizen T, van de Pol H, Wedel M, Schaafsma G: Effects of moderate dose of alcohol on blood lipids and lipoproteins postprandially and in the fasting state. Alcohol Alcohol 1990;25:371-377.

34 Murray CJL, Lopez A: The Global Burden of Disease: A Comprehensive Assessment of Mortality and Disability from Diseases, Injuries and Risk Factors in 1990 and Projected to 2020. Boston, Harvard School of Public Health on behalf of the World Health Organization and the World Bank, 1996. 